\title{
A Study on the Literature Physiology of Mathematical Emotion for the New Way of Literature Education
}

\author{
Inkwa Park \\ Department of Korean Language and Literature, Korea University, Korea
}

Copyright $\mathrm{C} 2019$ by authors, all rights reserved. Authors agree that this article remains permanently open access under the terms of the Creative Commons Attribution License 4.0 International License

\begin{abstract}
The literary therapy is conducted by the emotions that the literary narratives arouse. The emotions are sometimes the spare emotions that are sorted emotions out and remained. The purpose of this study is to clarify the effect of literature therapy on the spaer emotions and to utilize it in literary therapy programs. The spare emotions appear as repetitions of 'emotions-emotions = spare emotions' when viewing the Gosijo several times. In this way, Gosijo, a unique form of Korean's poetry, factor out the real body of the emotion that the author intended in the last line. At this time, the reader feels catharsis. This catharsis is a spare emotion. This emotion energy is calculated by subtraction of emotion as follows. Parting minus Longing is Sadness. And Longing minus Sadness is Catharsis. Then there are spare emotions as 'Sadness', 'Catharsis'. This Catharsis is mathematical Sadness. We can call that the method of calculation is mathematical physiology. This spare emotion produces the effect of literary therapy. By this study, the effect of the literary therapy by subtraction of these Sijo emotions may increase the value of literature education in the future.
\end{abstract}

Keywords Gosijo, Literature Education, Delivery of Emotional Signals, Mathematical Sadness, Brownian Motion of Emotions

\section{Introduction}

The Literature therapy is conducted by the emotions that the literary narratives arouse. Usually, the emotion is that several emotions are combined and sensitive. And sometimes, the emotions are also the spare emotions that are sorted emotions out and remained. This spare emotion, such as emotions, which are sensitive, shows a high degree of emotion's depth and concentration. This study is about spare emotions. The spare emotions appear as repetitions of 'emotions-emotions = spare emotions' when viewing the Gosijo several times. When we read the Gosijos, we often see the ending line of " I am being sadness for it. "Why did they enjoy using this sentence in the Gosijo? What are the neurological implications between simple sentence "I am being sadness" and sentence "I am being sadness for it"? Korean's unique form of poetry, the Gosijo, is set in three lines of frames to induce either emotional union or emotional amplification or emotional mutation. At the end, Gosijo, factor out the real body of the emotion that the author intended in the last line. The first line implies the emotion to be printed from the last line, the next line expands the implication, and the last line twists the space between the lines made by the preceding sentences. The real body of emotion, which is the result of implication, is then sticking out. At this time, the reader feels catharsis. This catharsis is a spare emotion. That spare emotion, catharsis, is the energy of the magnetic field that occurs in two gaps between emotion and emotion twisted.

This process of literary therapy is carried out quickly in the nervous system of the human body. It is carried out rapidly by the delivery of emotional signals by short form Sijo. The body is not only neurophysiological reacting by the delivery of emotional signals by a large set of sentences. The concentration of emotional signals by Sijo is intense even by a single set of Sijo. The emotional response in 3 lines set in only one of the Sijo emits physiological magnetic fields. In the future, the function of these Sijos shows the potential for emotion correction by Sijos in many people body. These Sijo emotions may increase the value of literature education in the future.

Now we want to analyze a Sijo 'The parting day is today' among the Gosijos in this process. This is because the framework of the Gosijo shows well the effect of implication. This discussion is based on 'Neuropsychological contents' (Baars Bernard J and Gage Nicole M, 2010; Bryan Kolb, Whishaw Q lan, 2012; Cooper Geoffrey M and Hausman Robert E, 2011; H. S. Min, K. J. Chang, O. R. Kwon, S. Y. Lee, H. M. Lee \& H. A. Kim, 2011; Özmaden, Soter \& Özmade 2018), and is on the extension of this researcher's 'research papers' (Inkwa Park, 2015; 2016; 2017, 2018; Castro 2018; Pan, 2014; Vahdany and Gerivani, 2016). 


\section{The Flow of Implication}

The Implication of emotion by a Gosijo's sentence passes through the emotional channel of a narrative in the form of 'Input $\rightarrow$ Expand $\rightarrow$ Output'. Then, this implication pushes out emotions for healing. Let's analyze this narrational channel of emotions in the Sijo, 'The parting day is today.' The next Sijo 'The parting day is today' is included in the Perfection of Ancient Korean Sijo (H. G. Kim. et al., 2012: 811; Hassan \& Kommers 2018; Okpechi, et. al 2018). We are going to translate '임' into 'She.'

이별은 오늘이요 임 갈 길은 천리로다

나는 보내고 그릴만 하려니와

산첩첩 수중중하니 그를 슬퍼 하노라

This Sijo is interpreted as follows in English.

The parting day is today. Her path to go is a very long distance.

Although I will send and have longing for her,

I am being sadness for it that her path has many mountains and deep streams.

We can guess that the emotional outburst of the Gosijo narration, above-mentioned, is being spearheaded by the ion channel of the human body. It is because the emotional outburst is an electrical signal, and this electrical signal is transmitted by ion channels. Now let's discuss in detail the parts of emotional outburst (Okon 2018; Audu 2018).

\subsection{Feeling of Parting}

The first part narration of the Gosijo is the step to enter 'Parting.'

Table 1. Parting of you and I

\begin{tabular}{c|c|}
\hline I \\
(I am left alone)
\end{tabular}$\leftarrow$ Parting $\rightarrow \begin{gathered}\text { She } \\
\text { (She is leaved from me) }\end{gathered}$

In the first part "The parting day is today. Her path to go is a very long distance," 'I' and 'She' are separated. And the mountain path that 'She' is headed for is too long. Repeatedly reading the Sijo "The parting day is today," the emotional gap between 'parting' and 'a very long distance' is stimulated by the Sijo. Something deep sadness and feeling of loneliness in parting is caused by the shaking gap. And the feeling of sadness and loneliness that deeply engulfed evokes a defense mechanism. So sadness and loneliness are replaced by the longing of the next line by the defense mechanism. That doesn't mean that sadness, loneliness, or sadness of loneliness is completely gone. It is only latent, protrudes from the end line again causing a violent magnetic field of sadness.

\subsection{Longing as an Emotional Enzyme}

In the second line of this Gosijo, the longing that attracted the tension of the parting filled with sadness and loneliness is protrude. As a result, the second line is formed as "Although I will send and have longing for her."

Table 2. Longing for you

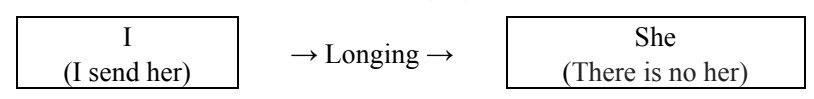

This longing appears in 'Parting' and faces 'She.' So the first line is the parting place, and the second line is the longing field.

\section{Catharsis of Narrative Emotions}

Now in the last line, emotions of sadness unleashed by the enzyme of separation, longing and sadness are appearing with powerful mag-netic field. It twists in emotions of parting, longing, and sadness, and wriggles in the twisting line another sadness different from the sadness before. "I am being sadness for it" is what removes the previous 'longing' and causes an amplification of sadness. So 'it' becomes 'minus' and forms the formula for "longing - Sadness" in relation to the previous longing. So it becomes "longing - Sadness $=$ Sadness." This is a more refined and dense sadness. The narration emotion emits the sadness and induces catharsis, so last line is the catharsis field. It is also a sad field. To this end, the practice of twisting the narration emotions is carried out. The sadness that brings catharsis is named in the name of sadness, but it is deep and burning beyond ordinary sadness. This is the sadness of 'longing' that has been deleted by "longing Sadness = Sadness" but still remains. Let's analyze this relationship. The effects of the emotion that emanates from the emotion channel of the Gosijo narration can be plotted in Table 6.

\subsection{Brownian Motion of Emotions}

The behavior that narration's emotional twist can be called 'Brownian Motion of Emotions.' This is because researcher in this study also supposes that emotions twist as doing Brownian Motion.

Table 3. Twisting between the parting and longing

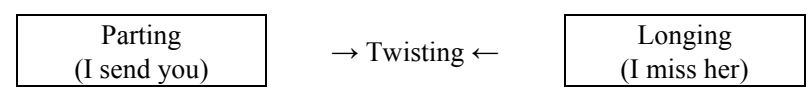

Table 4. Twisting between the longing and sadness

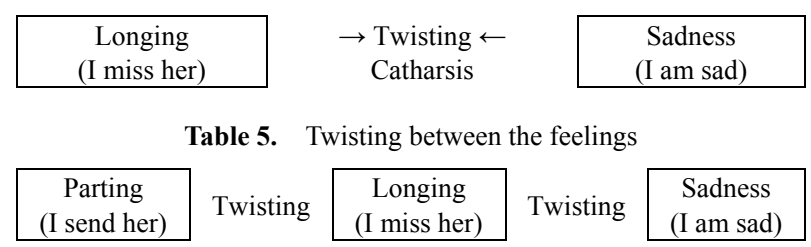

These Brownian Motion of emotions twist the emotions of 'Parting' and 'Longing' as shown in Table 3. Then, as shown in Table 4, they twist the emotions of 'Longing' and 'Sadness.' In addition, in Table 5, the all of Sijo's narrations twist and twist the emotions of 'Parting,' 'Longing,' and 
'Sadness' all together. That's Brownian Motion of narration emotions. This Brownian Motion brings out a deep sadness of loneliness. This is the purpose of this Sijo narration's Brownian Motion. Let's discuss this ignition of emotions using mathematical arithmetic.

Table 6. The flow of implication toward the effect of literary therapy

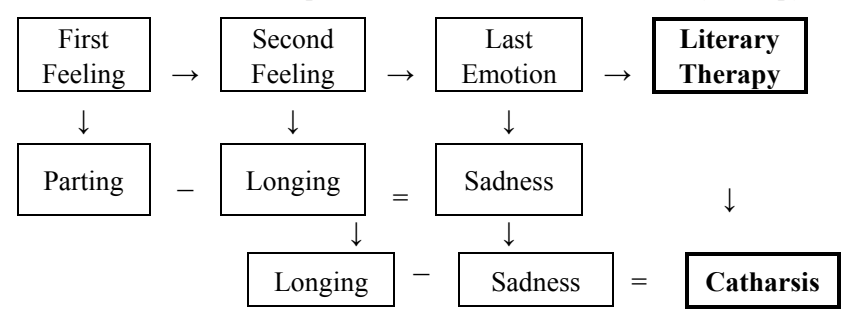

\subsection{Mathematical Emotions}

The Brownian motion of emotions produces the following subtraction emotions. Parting minus Longing is Sadness. And Longing minus Sadness is Catharsis. This Catharsis is Mathematical Sadness. Then there are spare emotions as 'Sadness', and 'Catharsis'. We can call that this method of calculation is mathematical physiology. These spare emotions make the effect of literary therapy.

\section{Conclusions}

Koreans' unique poem type, Gosijo, first implicates a spare emotion to be output at the last line, then expands that implication, and finally twists the lines' gap of the preceding lines. Then, the real body of emotion that the result of implication comes out. Through this process, literary therapy is carried out by the emotion that literary narration causes. The emotion is usually a sensitized emotion that is synthesized by various senses. And sometimes, they are spare emotions that calculated and remained. This study is about spare emotions. The repetition of "Emotion - Emotion = Spare Emotion" is repeatedly performed when we repeatedly appreciate the Gosijo of "The parting day is today". At this time, the reader feels catharsis. This catharsis is a spare emotion. The catharsis as a spare emotion of Gosijo narration is the energy of the magnetic field that occurs in the two lines' gap between an emotion and the other emotion that are twisting by the Brownian Motion.

The Brownian Motion of emotions as a narration emotion twists the emotions of 'Parting' and 'Longing.' And it twists the emotions of 'Longing' and 'Sadness.' In addition, the all narrations of Goijo carry out Brownian Motion by twisting emotions such as 'Parting,' 'Longing,' and 'Sadness' together. This Brownian Motion brings out the sadness of deep loneliness. This emotional energy is caused by subtraction of emotion. This is the Brownian Motion's purpose of this Gosijo narration. This Brownian motion produces the following subtraction emotions. Parting minus Longing is Sadness. And Longing minus
Sadness is Catharsis. Then there are spare emotions as 'Sadness,' 'Catharsis.' This Catharsis is mathematical Sadness. We can call that this method of calculation is mathematical physiology. These spare emotions produce the effect of literary therapy. The effect of the literary therapy by subtraction of these Gosijo emotions may increase the value of literature education in the future.

\section{REFERENCES}

[1] Audu, T. A. (2018). Effects of Teaching Methods on Basic Science Achievement and Spatial Ability of Basic Nine Boys and Girls in Kogi State, Nigeria. Humanities and Social Sciences Letters, 6(4), 149-155.

[2] Baars Bernard J and Gage Nicole M. Cognition, Brain, and Consciousness 1E. B. G. Kang trans (2010). Kyobo Books, 183-185.

[3] Bryan Kolb, Whishaw Q lan. An Introduction to BRAIN AND BEHAVIOR. H. T. Kim, M. S. Kim, J. J. Kim co-trans (2012). Sigma Press, 151-153, 309-312.

[4] Castro, M. (2018). A Didactic Experiment with Cinema-Portuguese Emigration and Sense of Belonging. Global Journal of Social Sciences Studies, 4(2), 70-77.

[5] Cooper Geoffrey M and Hausman Robert E. THE CELL A Molecular Approach. J. S. Jeon et al, trans (2011). World Science, 436-437, 544-548.

[6] H. G. Kim, H. T. Lee, S. W. Lee, Y. C. Kim, S. H. Kwon, K. S. Shin, G. H. Park compiled (2012). Perfection of Ancient Korean Sijo. Seoul: National Cultural Institute of Korea University.

[7] H. S. Min, K. J. Chang, O. R. Kwon, S. Y. Lee, H. M. Lee \& H. A. Kim (2011). Human physiology. Paju: Yangseowon, $59,146$.

[8] Hassan, M. I. A., \& Kommers, P. (2018). A Review on Effect of Social Media on Education in Sudan. International Journal of Educational Technology and Learning, 3(1), 30-34.

[9] Inkwa Park (2015). A Study on the Literature Therapy Using Sijo. JCCT, 1(1), 37-64.

[10] Inkwa Park (2016). A Study on the Literature Therapeutic Use of Sijo. Kyungpook National University. Master's Thesis.

[11] Inkwa Park (2017). A Study on Sijo Literature Therapy structuralized in the Rated Codon. The International Journal of Advanced Culture Technology, 5(2), 9-18.

[12] Inkwa Park (2017). Sijo Literature Therapeutic Research on Structuring of Emotion-DNA. The International Journal of Advanced Culture Technology, 5(1), 26-31.

[13] Inkwa Park (2018). Addition and Subtraction of Emotion Codons Igniting by Sijo. The International Journal of Advanced Culture Technology, 6(3), 117-128.

[14] Inkwa Park (2018). Literary Therapeutics of Brownian Motion in Hwang Jin-yi's Sijo. The Journal of the 
Convergence on Culture Technology, 4(3), 159-163.

[15] Okon, P. E. (2018). Comparative Analysis of Mass Media Coverage of the Fight against Corruption in Nigeria by the Obasanjo and Buhari Administrations. International Journal of Emerging Trends in Social Sciences, 4(2), 47-57.

[16] Okpechi, P. A., Denwigwe, C. P., Asuquo, P. N., Abuo, C., \& Unimna, F. U. (2018). Awareness and Utilization of e-Learning Resources by Trainee Counsellors of Counselling Education in Calabar, Nigeria. International Journal of Educational Technology and Learning, 3(2), 45-51.

[17] Özmaden, M., Soter, F., \& Özmaden, H. (2018). The Physical Education and Sport Studies in the Framework of Social Demands-Institutional Structuring and Teacher Training the Developments before and during Turkey Training Community Alliance Period (1922-1936). Asian Journal of Education and Training, 4(3), 170-175.

[18] Pan, C. Y. (2014). Effects of Reciprocal Peer-Questioning Instruction on EFL College Students English Reading Comprehension. International Journal of English Language and Literature Studies, 3(3), 190-209.

[19] Vahdany, F., \& Gerivani, L. (2016). An analysis of the English language needs of medical students and general practitioners: A case study of Guilan University of Medical Sciences. International Journal of English Language and Literature Studies, 5(2), 104-110. 